Peñalver Carrascosa, T. (2018): “Nueva propuesta interpretativa de la Domus del Peristilo de Lucentum (Tossal de Manises, Alicante)", Spal 27.2: 247-262. DOI: http://dx.doi.org/10.12795/spal.2018i27.22

\title{
NUEVA PROPUESTA INTERPRETATIVA DE LA DOMUS DEL PERISTILO DE LUCENTUM (TOSSAL DE MANISES, ALICANTE)
}

\author{
NEW INTERPRETATION OF THE DOMUS DEL PERISTILO OF \\ LUCENTUM (TOSSAL DE MANISES, ALICANTE)
}

\author{
TAMARA PEÑALVER CARRASCOSA \\ Departamento Prehistoria, Arqueología e Historia Antigua, Universidad de Valencia. \\ Facultat de Geografia i Història (Edifici Departamental. 1a i 2ª planta). Avda. Blasco lbáñez, 28, 46010 Valencia \\ Correo-e: tamara.penalver@uv.es ORCID: http://orcid.org/0000-0002-4072-229X
}

\begin{abstract}
Resumen: En el campo de la arquitectura doméstica romana es necesaria la revisión de determinados espacios excavados a comienzos del siglo pasado para estudiarlos desde perspectivas actuales, superando los rígidos cánones de la casa itálica y valorando las peculiaridades que afectan al diseño y construcción de una vivienda, como la topografía del terreno y la disponibilidad de espacio edificable. Nuestro objetivo es realizar una revisión de la Domus del Peristilo (Lucentum), analizando desde un punto de vista arquitectónico y funcional los espacios que la componen. Para ello plantearemos un estudio de paralelos que presentan problemáticas espaciales y soluciones constructivas similares.
\end{abstract}

Palabras clave: Arquitectura doméstica romana; técnicas constructivas.

\section{INTRODUCCIÓN}

El objetivo de este artículo es revisar una de las viviendas más emblemáticas del municipium romano de $\mathrm{Lu}$ centum (Tossal de Manises, Alicante). La particularidad de esta vivienda altoimperial, excavada a comienzos del s. XX, es su adaptación a la topografía urbana y a la falta de espacio edificable, ubicándose sobre la muralla púnica preexistente inutilizada en estos momentos (fig.1). Para poder ampliar el espacio edificable, el constructor
Abstract: In the field of Roman domestic architecture, we must review again certain spaces excavated at the beginning of the last century, in order to analyse them from current perspectives, getting over the idea of the old Italic house-type and valuing the peculiarities that have an impact over the design and construction of a house, such as the topography of the land and the availability of building space. Our aim is to review the Domus of the Peristyle (Lucentum), analysing the spaces that compose it from an architectural and functional point of view. In order to do this, we propose a study of some parallels that present similar spatial problems and constructive solutions.

Keywords: Roman domestic architecture; construction techniques.

adoptó una solución constructiva conocida como substrucciones que, además, genera una serie de estancias en las que pudieron desarrollarse funciones de servicio. Estos elementos condicionarán todos los aspectos de la domus, desde sus materiales y técnicas constructivas, hasta su distribución funcional. Por otra parte, estos aspectos no han sido nunca analizados, razón por la que creemos necesario estudiar, mediante la confrontación con paralelos, el sistema constructivo de esta vivienda y la funcionalidad de las estancias que la componen. 


\section{CONTEXTO HISTÓRICO Y UBICACIÓN DE LA DOMUS DEL PERISTILO}

Situada sobre una colina a $38 \mathrm{~m}$ sobre el nivel del mar y a tan solo $3,5 \mathrm{~km}$ al NE del actual casco histórico de Alicante, la antigua ciudad de Lucentum (3 ha), destaca como una de las escasas ciudades romanas valencianas que no ha sufrido ningún expolio por las construcciones de épocas posteriores (Fernández 2000-2001: 215; Olcina 2006: 105).

De origen cartaginés, registra la primera intervención edilicia de corte romano en el primer cuarto del s. I a.C. con la construcción de una nueva muralla de cariz militar, que sigue exactamente el circuito púnico previo, motivada por las crisis bélicas de finales de la República (Olcina y Pérez 2003: 91-108; Olcina 2006: 109). Su posición estratégica entre Ebusus, Dianium y Carthago Nova, fue determinante en su reocupación, convirtiéndola en un importante enclave en las rutas de navegación (Olcina et al. 2015: 255-257).

La concesión del estatuto jurídico de municipium se establece hacia el 26-25 a.C. (Älfoldy 2003: 45-47; Olcina et al. 2015: 255-257). Por tanto, es con Augusto y la dinastía julio-claudia cuando asistimos al máximo esplendor de Lucentum. En este período se erigirán los dos conjuntos termales; se eliminarán los elementos militares de la Puerta Oriental, convertida en un símbolo de prestigio urbano; se remodelarán las redes de saneamiento y abastecimiento de agua; y se reordenarán el parcelario y el viario urbanos. La ciudad no sobrepasó el lienzo murario, por lo que los intentos de ortogonalidad dieron lugar a ciertas tensiones en el tejido urbano. El trazado de dos de las principales calles, la calle de Popilio y la calle del Foro, que pueden corresponderse respectivamente, con el cardo y el decumano máximos, marca un primer foro, que determinará la posición del posterior foro altoimperial (Olcina 2009: 45-53; Sarabia 2013: 171).

El declive es evidente desde el s. I d.C., apreciándose en la colmatación de la cloaca, prueba de la ausencia de mantenimiento de las infraestructuras públicas. A mediados del s. II d.C., se generalizan los expolios, las colmataciones de cisternas, el cambio de funcionalidad de los espacios y la pérdida del entramado urbano altoimperial (Olcina 2009: 56).

La domus analizada en el presente artículo se encuentra situada en el ángulo SE de la ciudad, entre la calle que lleva su mismo nombre y la muralla púnica, posteriormente republicana. Su construcción sería posterior al 20-15 a.C., de manera simultánea a la urbanización de la parte oriental del enclave, la repavimentación de la plaza del foro y la construcción de, probablemente, la Domus del Mosaico. Diversas son las razones que propician la morfología de esta domus, que no responde a los modelos idealizados extraídos de las fuentes clásicas y actualmente superados por la investigación. Es un buen ejemplo de cómo la arquitectura provincial se adaptó a diferentes condicionantes, como la topografía urbana y la falta de espacio edificable, que impiden que podamos hablar de un canon en arquitectura doméstica (Tarradell 1970: 7-28).

\section{DESCRIPCIÓN Y ANÁLISIS DE LA DOMUS}

En 1931 Lafuente excavó la parte meridional del yacimiento, centrando su atención en su muralla y zonas adyacentes, donde apareció la domus objeto de estudio. Lafuente (1932) definió el primer y tercer tramo del lienzo defensivo, como un barrio con muchas casas adosadas a la muralla, tanto en su cara interna como externa, algunas reaprovechando las torres. Tras su excavación a principios de siglo, esta domus se ha visto sometida a expolios, alteraciones, incluso reconstrucciones poco acertadas que han priorizado la muralla. En consecuencia, no podemos conocer la morfología completa de la casa, al haber sido destruidas algunas de sus estancias principales.

Como ya hemos dicho, este espacio se excavó en fechas muy tempranas y sin una metodología detallada, por lo que nuestro conocimiento sobre el mismo es restringido y fragmentario, y no nos permite datarlo de manera exacta. Sin embargo, hay tres hechos que nos remiten a su datación en el s. I d.C.: no se ha atestiguado un proceso urbanizador en Lucentum previo a la época augustea; su construcción se realizó anulando la muralla que definía los límites urbanos púnicos, proceso que sucede de forma contemporánea en el lado oriental del yacimiento hacia el cambio de Era; y la excavación del drenaje del patio porticado y el colector de la calle por la que se accede a la domus, sitúa a inicios del segundo cuarto del s. I d.C. su colmatación, por lo que las estructuras estaban plenamente en uso en esos momentos (Olcina et al. 2015: 258).

La vivienda cuenta con $400 \mathrm{~m}^{2}$ estimados (fig.2) (tabla 1), cuyas características indican que el propietario podría ser un miembro de la élite local, con una riqueza acorde a un municipium de 3ha, no comparable con colonias como Valentia o grandes municipia como Saguntum. Del mismo modo que en Ilici, parece que los edificios de carácter privado fueron emplazados en los límites del pomerium de la ciudad, donde había una 


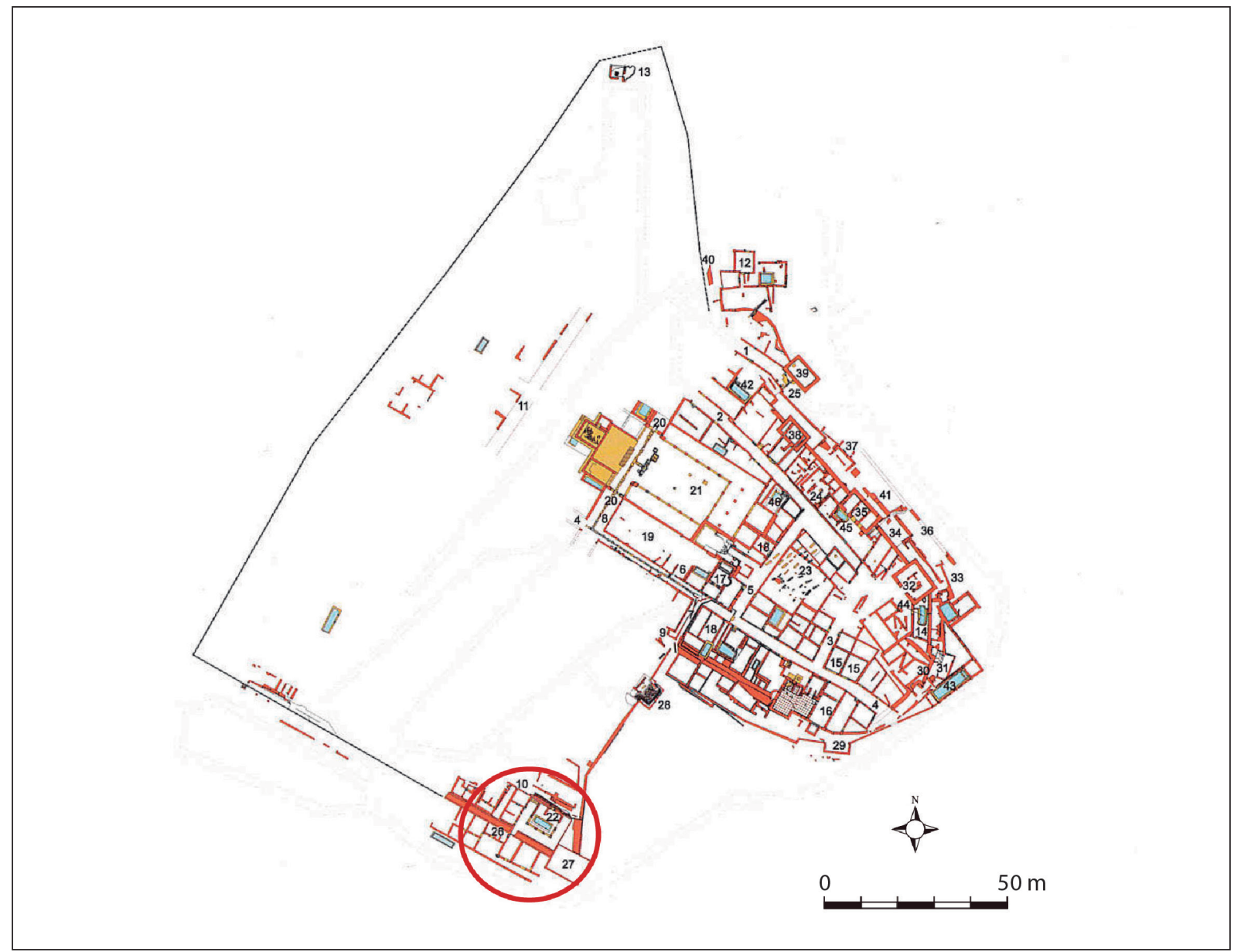

Figura 1. Ubicación de la Domus del Peristilo (Olcina et al. 2014: 210, fig. 7).

mayor disponibilidad de espacio para construir suntuosas domus. Dos de las tres viviendas romanas conocidas en el yacimiento se encuentran en esta situación, tanto la Domus del Peristilo, que fue levantada inutilizando un tramo del lienzo SE de la muralla, como la Domus de la Puerta Oriental que hizo lo propio en la parte NE.

\subsection{Ambientes internos a la muralla}

La entrada a la domus, con sus 2,6 m de luz, se sitúa en el extremo NO del pórtico. Se trata de un acceso directo al patio principal, es decir, no cuenta con un vestíbulo o fauces que funcionen como elementos de transición entre la calle y el ambiente distribuidor. Esta solución constructiva posibilita alcanzar rápidamente el corazón de la casa y aparece asociada a casas modestas que disponen de poco espacio edificable. En época altoimperial los constructores no suelen desviarse del modelo establecido, así que cuando eliminan el ingreso no se trata de una elección programática, sino de una necesidad condicionada por un lote edilicio demasiado escaso o mal orientado. A pesar de ser algo considerado anómalo, es una solución difundida por todo el Imperio (Bonini 2006: 46-49). Esta premisa parece cumplirse en la Domus del Peristilo, ya que tanto su posición en un área periférica de Lucentum, desarrollándose sobre la muralla púnica, como su adaptación al urbanismo son indicios de la falta de espacio edificable.

La elevación de la cota de la calle, al construir la cloaca hacia el cambio de Era, supondrá adaptaciones incómodas en el acceso a las viviendas. De este modo, la domus construye su acceso mediante una escalera de tres peldaños, pues el nivel de circulación de la casa se encuentra más bajo que el de calle (Olcina 2009: 106-108). 
Tabla 1. Dimensiones de las estancias que componen la Domus del Peristilo.

\begin{tabular}{|c|c|c|}
\hline Estancia & $\begin{array}{c}\text { Dimensiones obtenidas } \\
\text { de la planimetría }\end{array}$ & Superficie \\
\hline 1 & $6,50 \times 6,70 \mathrm{~m}$ & $43,50 \mathrm{~m}^{2}$ \\
\hline 2 & $3,20 \times 3,80 \mathrm{~m}$ & $12,16 \mathrm{~m}^{2}$ \\
\hline 3 & $2,80 \times 3,60 \mathrm{~m}$ & $10,00 \mathrm{~m}^{2}$ \\
\hline 4 & $2,20 \times 3,60 \mathrm{~m}$ & $7,90 \mathrm{~m}^{2}$ \\
\hline 5 & $12,75 \times 1,72 \mathrm{~m}$ & $21,93 \mathrm{~m}^{2}$ \\
\hline 6 & $5,51 \times 2,58 \mathrm{~m}$ & $14,21 \mathrm{~m}^{2}$ \\
\hline 7 & $5,86 \times 4,82 \mathrm{~m}$ & $28,24 \mathrm{~m}^{2}$ \\
\hline 8 & $6,03 \times 3,44 \mathrm{~m}$ & $20,74 \mathrm{~m}^{2}$ \\
\hline 9 & $5,00 \times 5,86 \mathrm{~m}$ & $29,30 \mathrm{~m}^{2}$ \\
\hline 10 & $3,62 \times 3,27 \mathrm{~m}$ & $11,83 \mathrm{~m}^{2}$ \\
\hline 11 & $3,44 \times 4,65 \mathrm{~m}$ & $15,99 \mathrm{~m}^{2}$ \\
\hline
\end{tabular}

El elemento redistribuidor (1) de la vivienda presenta las características propias de un espacio descubierto porticado únicamente en tres de sus lados. Adosado al muro perimetral NE de la vivienda, el pórtico presenta forma de $\mathrm{U}$ con seis pilares o columnas de sección cuadrangular, unidas entre sí por un pluteus de mampostería revocada de argamasa de cal que servía para delimitar el espacio abierto. A pesar de que los investigadores lo han definido tradicionalmente como ajardinado, lo cierto es que no contamos con indicios en la reconstrucción actual que permitan corroborarlo. Aunque no se hace mención en las diversas publicaciones al pavimento del mismo, se preservan molduras de media caña en la parte interior del pluteus que estarían indicando la existencia de un suelo de opus signinum en el espacio descubierto. Este patio albergaba un estanque a ras de suelo $(1,6 \mathrm{~m}$ x 4,8 m) dedicado a la captación de agua de lluvia, con un recubrimiento hidráulico de opus signinum y molduras de media caña (Olcina 2009: 106-108). No se tiene constancia de los sistemas de drenaje de esta balsa, ni sabemos si existiría una cisterna subterránea. Sin embargo, la esquina E de la estructura hidráulica presenta una acanaladura que indicaría que el agua caída en el patio se vertería al interior de la misma; razón de más para corroborar la teoría de que nos encontraríamos frente a un espacio distribuidor pavimentado. La anchura del espacio porticado circundante, $2,6 \mathrm{~m}$, se calcula en función del corredor conservado en el lado NO del mismo.
Tras este análisis, y si la distinción entre peristilos y patios porticados se basa en que el espacio esté ajardinado, en el caso de los peristilos, o pavimentado, en el caso de los patios porticados (Cortés 2014: 1013-1017), podríamos calificar este distribuidor, siempre teniendo en cuenta la dificultad arqueológica de identificación de estos espacios por cuestiones de preservación, como patio porticado.

El hecho de que encontremos este tipo de espacios en ambientes provinciales es un reflejo de cómo los habitantes de Lucentum asumieron el modus vivendi romano, una muestra más del éxito de la aculturación (Meyer 1999: 118-119). Por tanto, a pesar de que su posición dentro de la vivienda, con la entrada situada en el pórtico occidental, no presente una disposición axial, este espacio asume la función de módulo integrador de los diversos ambientes residenciales, tales como los cubicula y los ambientes de representación (Sarabia 2013: 174-177).

Al NO se abren tres estancias (2, 3 y 4) que por su uniformidad morfológica han sido identificadas por los excavadores como cubicula o dormitorios (Olcina 2009: 106-108). Las tres presentan dimensiones semejantes con longitudes que oscilan desde los 3,6/3,8 $\mathrm{m}$ y anchuras entre 2,2/3,2 $\mathrm{m}$. A pesar de la uniformidad morfológica, las reducidas dimensiones de las estancias y de sus umbrales de acceso, y su ubicación en planta, abiertas al patio porticado y separadas de las salas de representación, no contamos con ningún otro indicio que nos permita inferir la funcionalidad de las mismas.

Presuponemos que al $\mathrm{S}$ del patio porticado se abrirían otras estancias ( $\mathrm{a}, \mathrm{b}$ y c), que fueron arrasadas en 1980 durante las labores de reconstrucción de la estructura defensiva púnica. Si reprodujésemos, a la misma cota del patio, el esquema de los muros que se conservan al exterior de la muralla, podríamos reconstruir tres salas rectangulares paralelas (fig. 3).

De ser así, la casa no cumpliría con el precepto de las "axial peristyle houses" de Meyer (1999: 102103), por no contar con una alineación directa del acceso-peristilo/patio porticado-estancias de representación. Sin embargo, sus supuestas dimensiones y ubicación en planta, abiertas al lado largo del patio, ayudarían a identificarlas como como salas de representación (Olcina 2009: 106-108) y encajarían perfectamente en los análisis de accesibilidad (análisis gamma) y de visibilidad (isovistas) realizados por Sarabia (2013: 180) (fig.4).

Existen diversos ejemplos como en la Maison des Fauves y la Maison de Flavius Germanus en Volubilis 


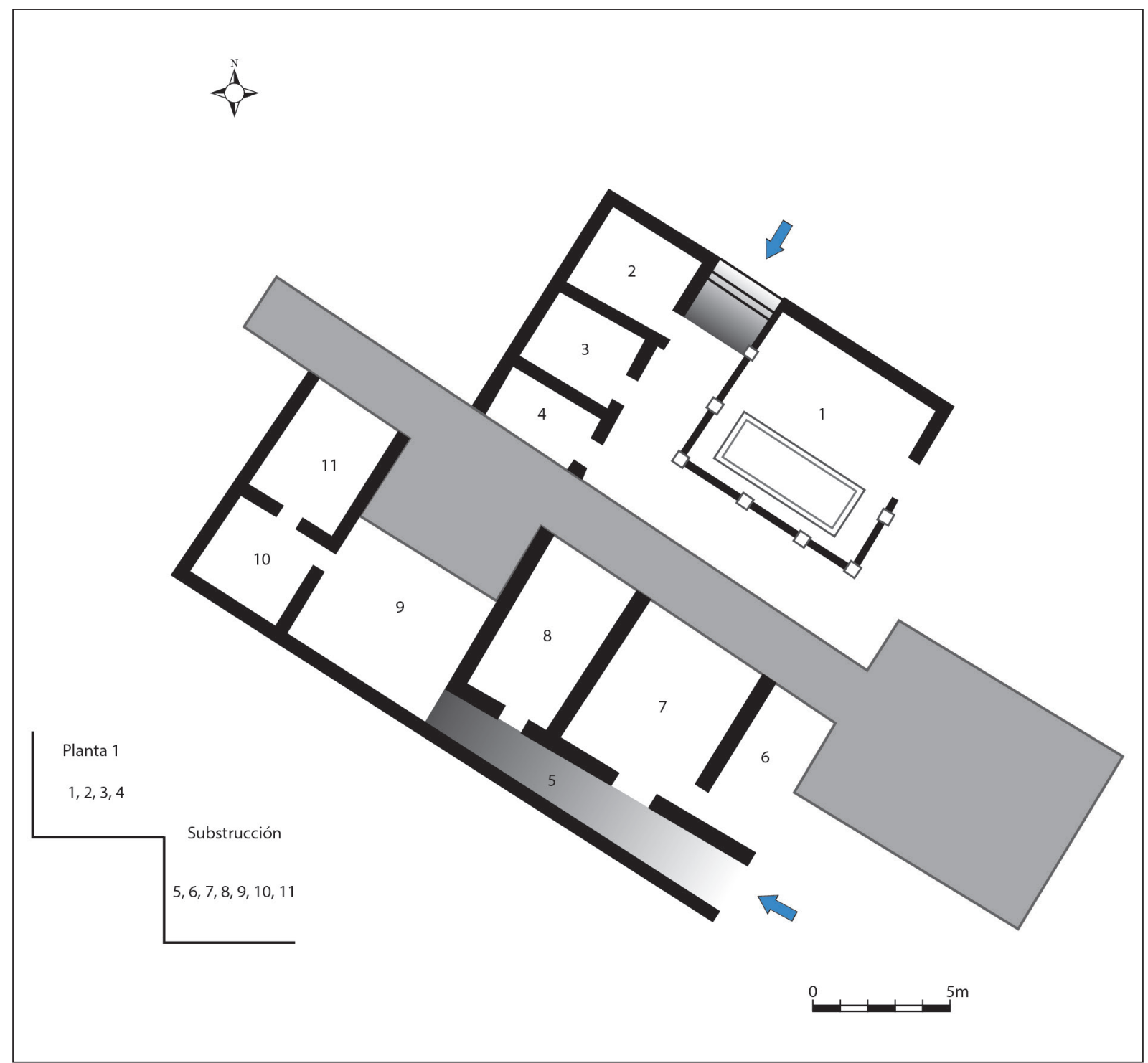

Figura 2. Domus del Peristilo (plano de la autora, a partir de Olcina 2009: 106).

o la Maison aux consoles en Apamea, donde la visión directa del triclinium no es posible, solo cuando el visitante se sitúa en la entrada del vestíbulo hacia el peristilo la visión se abre hacia el patio interior y la sala de convivium. En este caso, estas estancias no se encontrarían a la vista de los viandantes, lo que aumenta su nivel de privacidad (Meyer 1999: 105-107).

Sin embargo, nos gustaría matizar que todas estas hipótesis resultan poco fundadas, teniendo en cuenta que ni tan siquiera conservamos las estructuras en planta de las supuestas estancias de representación, solo una imagen proyectada, fruto de la observación de las estancias inferiores. Recordemos que tras la reconstrucción de los años ochenta del siglo pasado, solo conservamos el patio porticado y la muralla púnica (fig. 5).

La zona al SE de la vivienda, que ocuparía el área de la torre II de origen púnico y el tramo de la muralla hasta la calle, es más compleja de interpretar. Aunque no nos es posible identificar su función, es difícil que no formara parte de esta vivienda. En ella podrían situarse un hortus o más estancias de representación, como ocurre en la Domus de la Puerta Oriental, que en su segunda fase se amplió al construir un patio con balsa de captación de agua sobre una de las torres (O1cina 2009: 106-108) (fig.6). 


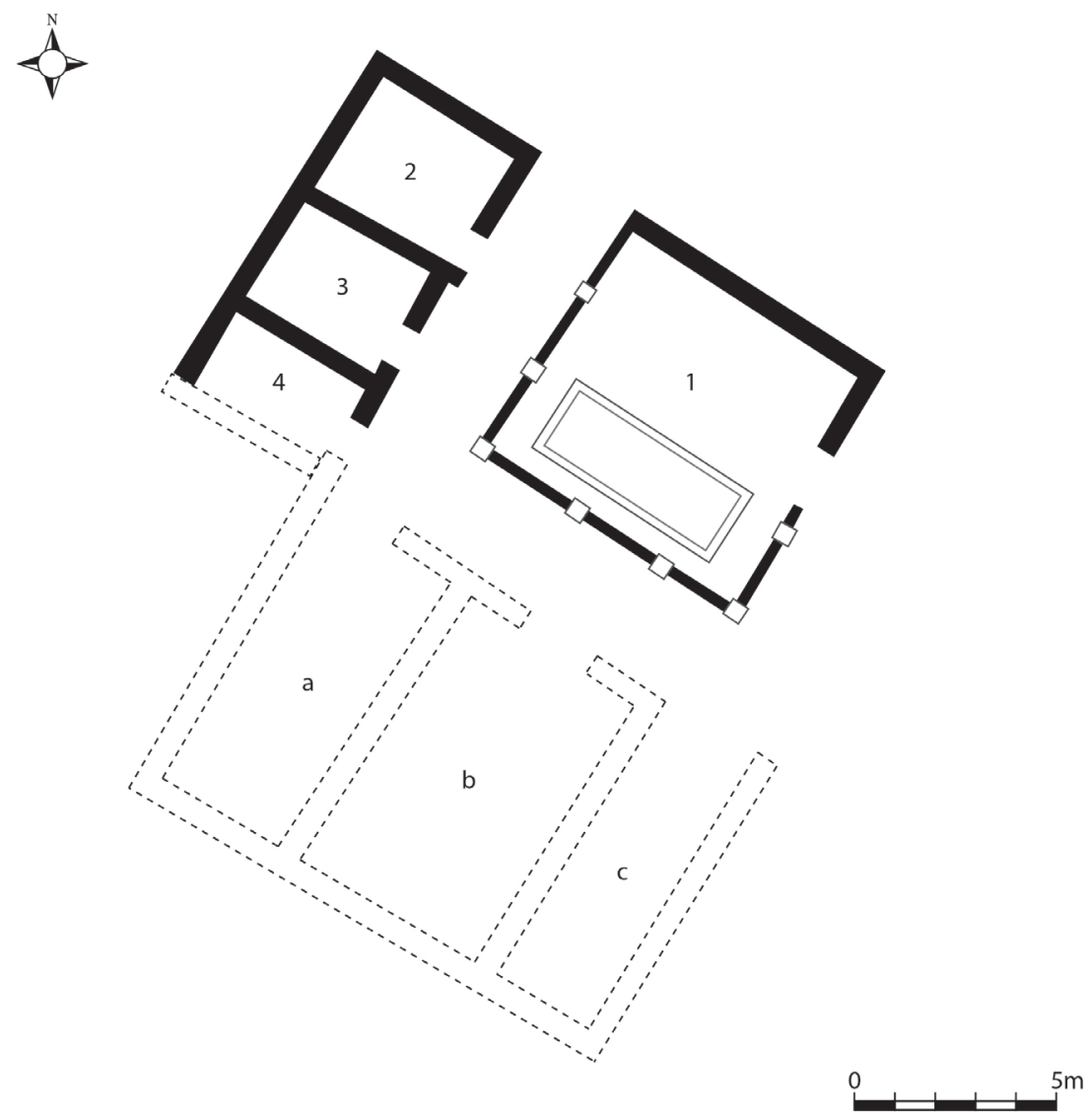

Figura 3. Reconstrucción hipotética del primer nivel de la Domus del Peristilo (plano de la autora a partir de Olcina 2009: 106).

\subsection{Ambientes externos a la muralla}

En una cota inferior, con más de 2 metros de desnivel y adosados a la cara externa de la muralla encontramos cinco departamentos.

El acceso a los mismos se realizaría a través de un corredor (5), aparentemente de servicio, que haría las veces de distribuidor, dando acceso a tres grandes estancias (6, 7 y 8). Este pasillo termina en un espacio de tendencia cuadrangular (9), que podría funcionar como patio. A él se abre la estancia 10, que aparece conectada interiormente con la estancia 11, ya que no tiene vano abierto al espacio distribuidor 9, por lo que se define como una estancia auxiliar de la anterior.

Al examinar estos ambientes, surgen dos posibles hipótesis: que formaran una sola unidad doméstica junto con las estancias ubicadas en el interior de la muralla o que sirvieran de sustento arquitectónico a la planta superior, pero que constituyeran una vivienda independiente.

En caso de formar parte de la misma domus, dada la cota de esta planta, estos espacios podrían estar desempeñando funciones de servicio tales como almacenes y cocina, mientras servirían de base estructural para el piso superior situado a la cota del patio. Es posible que ambos pisos estuvieran conectados a través de una escalera, cuya caja no se ha conservado, pero que podría ubicarse en la estancia 6 por su morfología alargada y estrecha. Somos conscientes de la prudencia que exigen los restos conservados a la hora de elaborar una hipótesis de estas características, pero consideramos que la ubicación de ambas plantas y la técnica constructiva de la planta inferior podrían estar indicando una conexión entre ellas, a pesar de no haberse conservado el indicio material de una escalera (fig.7). 
Figura 4. Análisis de visibilidad y accesibilidad de la Domus del Peristilo (Sarabia 2013: 180, fig.6).
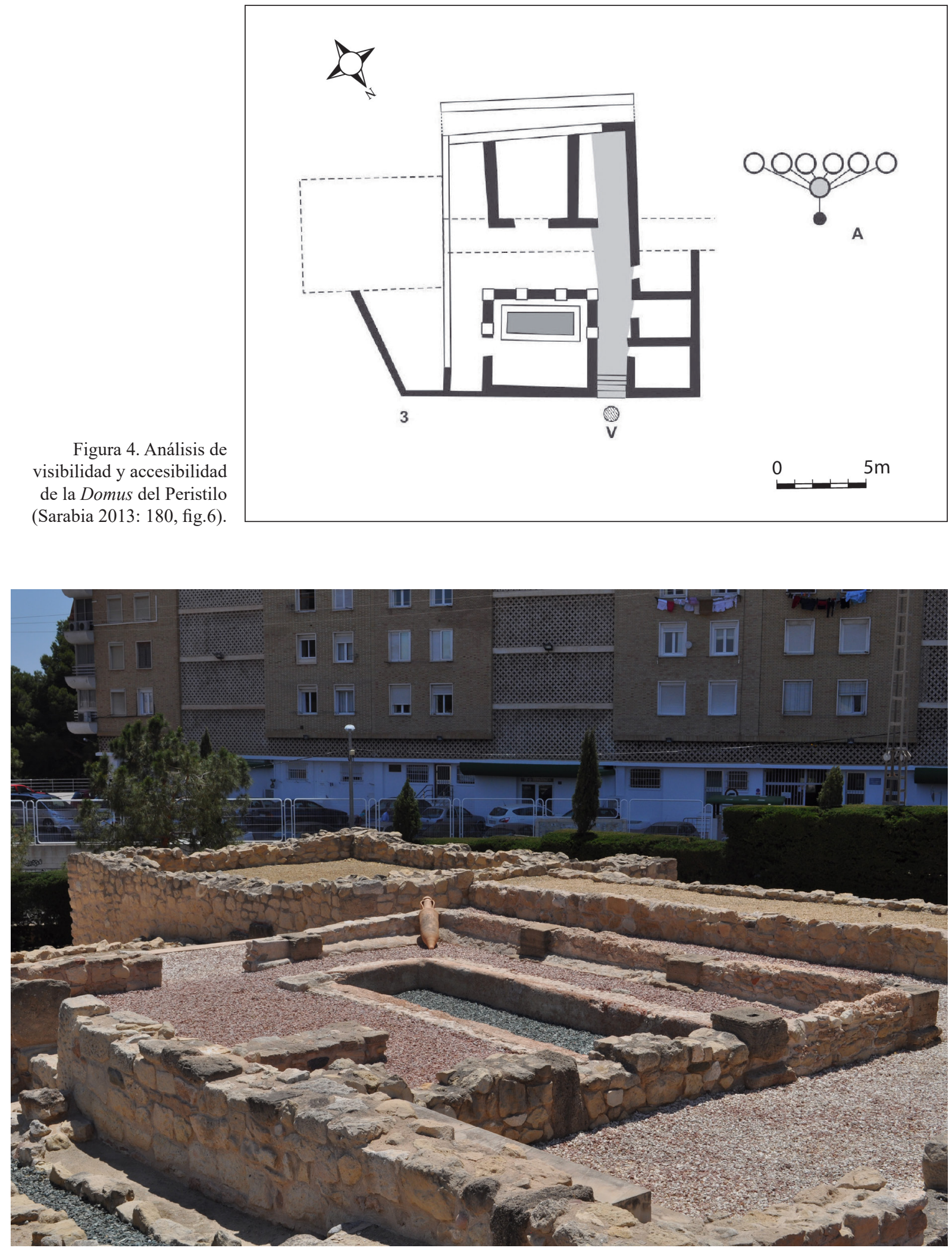

Figura 5. Estado actual de la Domus del Peristilo.

ISSN: $1133-4525$ ISSN-e: 2255-3924 


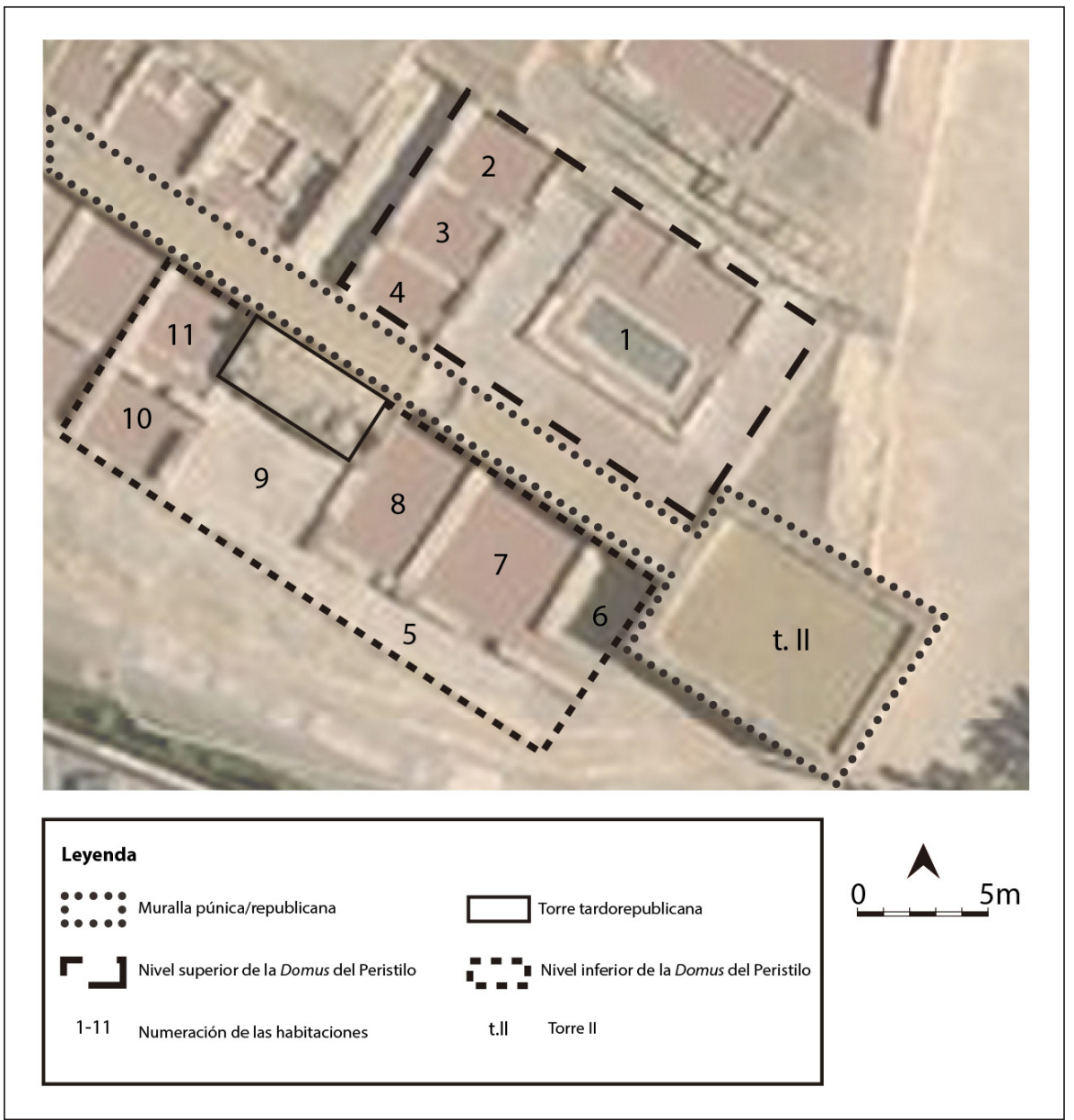

Figura 6. Fotografía aérea del estado actual de la vivienda.
El grosor de los muros de las estancias inferiores es de $60 \mathrm{~cm}$, diez centímetros más que los muros de la planta superior, que oscilan en torno a los 50 $\mathrm{cm}$, por lo que este aumento estaría indicando que estos muros podrían soportar las estructuras de una segunda planta.

No sorprendería que estas tres estancias $(6,7$ y 8$)$ se pudieran dedicar a espacios de almacenamiento, con diversos términos latinos aplicables en función de lo que se guardara en ellos: cellae vinariae para la fermentación del vino, oleariae para el aceite, penarie para provisiones generales, apothecae para conservar el vino, horrea o granaria para el grano, oporothecae para la fruta o cellae para alojar a los siervos domésticos. Generalmente, estos almacenes se caracterizan por su amplitud, por la presencia de umbrales anchos, fácilmente alcanzables desde los ingresos posteriores, para poder introducir mercancías. Además, forman áreas constituidas por numerosos locales de diversas morfologías, normalmente dotados de tomas de luz y aire y unidos por uno o más ambientes de distribución (Basso 2003: 522-546). Todas estas características se cumplen en las estancias 6, 7 y 8 de la Domus del Peristilo (Lucentum).

Las estancias 10 y 11 pudieron constituir una posible cocina y/o almacén, conectadas entre sí, como podemos ver en la Casa Norte del yacimiento de Arucci, donde se han identificado dos estancias, la $\mathrm{H} 4$ como la cella penaria, que tiene acceso al espacio distribuidor y la H5 como la culina, a la que solo se tiene acceso a través de la sala penaria (Corrales et al. 2016: 210). Las cocinas en substrucciones presentan algunos problemas respecto a los factores de proximidad y accesibilidad (Foss 1994: 39), como el paso de los alimentos entre esta área y el triclinium, interrumpido por unas escaleras. Sin embargo, respecto a la percepción, esta distribución contribuía a aislar de olores y ruidos la parte noble, prevaleciendo la voluntad de marginar los espacios serviles a cualquier coste, alejando los olores 


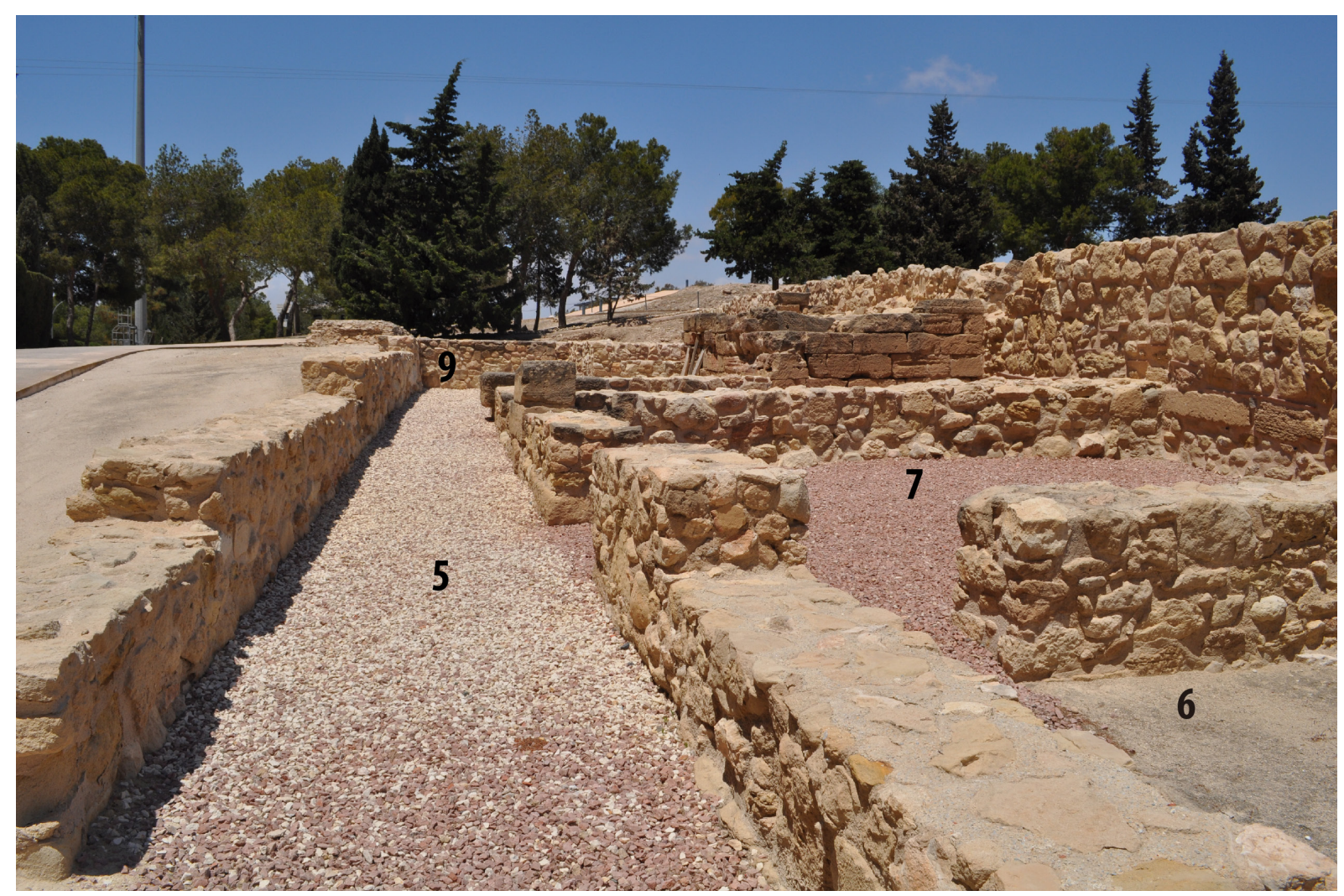

Figura 7. Domus del Peristilo, estancias externas a la muralla.

y la suciedad de las habitaciones residenciales (Bonini 2016: 461; Kastenmeier 2007: 31-35).

La forma en L del nivel inferior de la Domus del Peristilo presenta paralelos en el corredor 18 del edificio dei tre Bacini en Thuburbo Maius, que recoge tres pequeños ambientes artesanales, o la Casa dell'Efebo en Volubilis, con el mismo sistema (Bonini y Rinaldi 2003: 208),

Nos inclinamos por esta hipótesis, ya que las cocinas se solían ubicar en ambientes internos de la casa, con dimensiones reducidas que no suelen superan los 10-15 $\mathrm{m}^{2}$. Además, sobre estas dos estancias (10-11) no hay indicios de una segunda altura, por lo que podría situarse aquí la salida de humos de la cocina, ya que la ventilación es un factor esencial para estas estancias. Si no, se podían ubicar ventanas a la calle, o en caso de encontrarse en lugares interiores se podía situar un agujero en el techo, tégulas agujereadas, etc (Kastenmeier 2007: 58-60).

No debemos olvidar que la ubicación de los sectores de servicio aparece subordinada a las áreas residenciales, por lo que son los que más flexibilidad presentan en su organización arquitectónica, ya que siguen criterios pragmáticos. Parece claro que la posición ideal de una cocina era próxima a un ingreso, lateral o posterior (posticum), con una cierta distancia de las estancias residenciales. Por tanto, la ubicación de estas habitaciones, que podrían sostener el segundo piso y que presentan un acceso independiente que facilitaría el acceso a esta área sin interferir en la planta noble, apoya nuestra hipótesis. Además, la existencia de un sector servil separado físicamente de la parte pública de la casa indica una disponibilidad económica considerable, como ocurre en la casa del Centenario o la Casa del Laberinto (Pompeya) (Salza 1978-1980: 266-267).

Sobre la planimetría podemos decir que, mientras en las áreas nobles los ambientes se distribuyen en torno a espacios descubiertos porticados, las estancias de servicio se suelen disponer en espacios organizados por un largo pasillo o, en algunos casos, en torno a patios de servicio (Salza 1978-1980: 267).

Por tanto, esta planta reúne tres de los elementos que nos ayudan a identificar los ejes de servicio: un acceso secundario independiente, la organización en torno a un pasillo y la presencia de patios redistribuidores o de servicio. 
Por último, no queremos pasar al siguiente punto sin plantear una alternativa igualmente factible para estas estructuras. Con base en el número de estancias y en la existencia de dos accesos diferenciados en ambas plantas, así como debido a la ausencia de una escalera u estructura que conecte ambos niveles, es inevitable plantear la posibilidad de que nos encontremos ante dos unidades domésticas independientes.

Evidentemente, y en vista de la técnica constructiva, que será analizada más adelante, ambos espacios estaban interconectados, aunque solo fuera mediante su sistema constructivo. El grosor de los muros inferiores, la presencia de sillares de refuerzo en las esquinas de los mismos y la morfología de la planta superior parecen confirmar la función de substrucción que cumplirían las estancias 6,7 y 8 respecto al piso superior. Sin embargo, podríamos encontrarnos con una casa propia de la élite provincial, con vistas panorámicas al mar, sostenida por una casa de corredor de 5 habitaciones, más modesta y relegada extramuros, alejada del centro de la urbe.

De ser así nos encontraríamos frente a dos unidades domésticas independientes, reflejo de una simbólica pirámide social donde la base la constituye un ambiente doméstico humilde y extramuros, sobre el que se construye una suntuosa domus de patio porticado, privilegiada con una posición intramuros junto a una vía con acceso directo al foro.

\section{SOLUCIONES Y TÉCNICAS CONSTRUCTIVAS}

Para poder comprender la complejidad de los fenómenos constructivos, es necesario superar los estudios formalistas y meramente descriptivos de la arquitectura romana. No debemos olvidar que un edificio es el resultado de un proceso muy complejo que aúna principios técnicos, elementos estéticos y necesidades funcionales (Roldán et al. 2017: 9).

Como ya hemos dicho, uno de los puntos más interesantes de esta domus es la presencia en el lienzo exterior de la muralla de cinco habitaciones que, de acuerdo con su morfología y el grosor de sus muros, podrían estar sosteniendo un segundo piso, necesario y lógico según la tipología de la casa, lo que las relacionaría con la Domus del Peristilo. Estas estructuras responderían al término constructivo de substructiones, entendido como el conjunto de obras que sostienen con muros una plataforma artificial (platea), sobre la cual se erigen edificios o áreas descubiertas, como plazas, calles y jardines. Existen diversas formas, simples y complejas.

Las condiciones morfológicas que imponían erigir substrucciones son básicamente dos: terrenos inclinados o explanadas insuficientes para albergar un edificio, por lo que era necesario extender la superficie con muros avanzados. En el caso de Lucentum se combinan ambas razones, un espacio edificable insuficiente y dos planos que presentan una diferencia de cota considerable. El edificio superpuesto casi nunca prescinde de las obras de sustento, ya que pueden aprovecharse para ubicar sistemas para evacuar el agua, locales de servicio (cantinas o cisternas) o ambientes lujosos (ninfeos y criptopórticos). Como ya hemos dicho, consideramos que es posible que las estancias de servicio de la domus estuvieran ubicadas en este nivel inferior, que podría estar conectado con un segundo piso a través de unas escaleras no conservadas. Por tanto, en este caso se trataría de una sostruzione cava, entendida por Zaccaria como un organismo articulado en el interior, con zonas llenas y otras vacías (Zaccaria 2003: 67-69).

Dentro de la tipología establecida por la autora, el caso de Lucentum se correspondería con el de ambienti sustruttivi funzionali (Zaccaria 2003: 91-92). Entre sus usos pueden estar los de cantina y despensa, como vemos en la Villa de Bagni di Lucilla en Poggio Mirteto (Rieti) o en la Villa de Cassio en Tívoli donde, en su segunda fase (s. II a.C.- inicios del s. I a.C.), encontramos un angosto corredor con ventanas, dividido en cinco locales y con pavimento que vertía hacia el exterior, con función de servicio (Zaccaria 2003: 98).

En Pompeya, contamos con paralelos en la Casa del Cinghiale (VIII 2, 26, 27), donde la cocina y sus dos espacios adyacentes, que funcionarían como letrina y lavadero, se encuentran formando parte de las estructuras substructivas. Del mismo modo, los subterráneos de la casa VIII, 2, 29, los de la Casa delle Colombe (VIII 2, 32-34), la Casa VIII, 2, 36 y la Casa di Giuseppe II (VIII 2, 38-39), entre otros, tienen también funciones de servicio (Kastenmeier 2007: 138-143).

En ciudades provinciales como Cartago, debido a la vertiente urbana, se crean cortes artificiales escalonados para crear un área llana en la que poder construir. Esto demuestra la importancia de la morfología del terreno. En Thugga, las estancias semienterradas aprovechan profundos escalones artificiales, como la Casa de la Gorgona con estancias de servicio semienterradas (almacenes y cisterna) que se comunican con la parte noble de la casa mediante escaleras (Bonetto 2003: 283-285). Por tanto, los yacimientos de Cartago, Thugga y Althiburos ofrecen una gran cantidad de ejemplos 
de empleo del subsuelo a lo largo de pendientes, con ambientes de alto valor estático-estructural destinados a desarrollar funciones de servicio, economizando los ambientes domésticos para poder sacar provecho del difícil espacio edificable.

La temprana cronología itálica para este tipo de construcciones (tardorrepublicana-altoimperial) implicaría que pudo haber una transmisión de experiencias arquitectónicas del centro del Imperio hacia las provincias (Bonetto 2003: 286-288).

En Hispania encontramos diversos ejemplos en los que espacios de servicio se ubican en substrucciones. La orografía de Bilbilis propició su construcción en terrazas, utilizando sus sótanos como zonas de transformación, como la terraza inferior de la Domus 1 donde se conserva un frente de tabernas (Uribe 2015: 207); los espacios inferiores de la Casa del Larario (anteriormente Casa del Ninfeo) con la presencia de un lagar (Uribe 2008: 130-132; Sáenz et al. 2005: 377-396); la Casa de Bámbola Corte I (BCI) o la Casa de las Escaleras, donde se preservan las substrucciones de una vivienda cuyos espacios interiores fueron utilizados como almacenes y bodegas (Uribe 2015: 234).

Las llamadas casas de Taracena o Casas del Sur (Tiermes) cuentan con habitaciones que se encuentran construidas parcialmente sobre paredes rocosas, que han perdido la planta superior y conservan el frente de obra, cuya parte baja amortizó la construcción de la muralla bajoimperial (García 2014: 1095). Salvando las distancias, es interesante relacionar nuestro caso de estudio con el yacimiento de Silla del Papa (Tarifa), donde se han encontrado viviendas de carácter rupestre de dos niveles apoyadas en el afloramiento rocoso natural, construidas con refuerzos tallados en la roca, datadas en época tardorepublicana (Moret et al. 2008: 2-8).

A pesar de que nos gustaría relacionar esta domus con otras evidencias de la propia Lucentum, para poder comprobar si este sistema fue una pauta en los ambientes domésticos de esta ciudad, la arquitectura doméstica de este yacimiento es uno de sus capítulos más desconocidos. Las excavaciones de los años 1931, 1936 y 1966-67 no identificaron ni registraron con detalle los posibles espacios domésticos, por lo que solo encontramos publicados tres ambientes presumiblemente privados, la Domus del Peristilo, la Domus de la Puerta Oriental y la Domus del Mosaico (Olcina 2009:104).

En conclusión, las estancias subterráneas tuvieron diferentes usos y se pueden dividir en espacios excavados en el subsuelo rocoso; habitaciones semisubterráneas, apoyadas en laderas y casas con dos o más plantas, parcialmente realizadas en la roca (García 2014: 1093).
La Domus del Peristilo podría insertarse en el segundo grupo, aunque en lugar de una ladera, la construcción apoyaría sobre una muralla.

Respecto a la técnica constructiva, en esta domus únicamente se conservan los zócalos de mampostería de opus incertum, realizados con calizas de mediano tamaño y con una anchura de $50 \mathrm{~cm}$ en el piso superior y de $60 \mathrm{~cm}$ en el piso inferior. Ambos pisos están construidos con los mismos materiales y la misma técnica, lo que apoya la hipótesis de que se trata de la misma unidad doméstica. Por otra parte, en ambos niveles observamos la reutilización de sillares de arenisca extraídos de la muralla previa, en concreto de la torre I, propia de la reforma republicana que se llevó a cabo sobre la muralla púnica, manteniendo el mismo trazado y ampliando el espesor de la misma. A su vez los materiales con los que se hicieron las nuevas torres republicanas, como la torre I, son bloques reutilizados de otras estructuras (Olcina 2006: 109).

En el caso del piso inferior de la casa, se puso especial cuidado en las esquinas de las habitaciones donde se ubican dichos sillares de arenisca (fig.8). Uribe (2015) define esta técnica como sillares esquineros, término acuñado por Lorrio para la Casa del Médico en Ercavica; una técnica constructiva utilizada en el valle del Ebro cuyo paralelo más cercano se encuentra en Arcobriga. Este material se emplea también en las columnas cuadrangulares del patio porticado, por lo que es evidente que al arrasar la muralla para construir la domus, esta sirvió como cantera para la construcción de la nueva vivienda, del mismo modo que observamos en otros lugares del yacimiento, como en la Domus de la Puerta Oriental, con la misma técnica y materiales constructivos.

Corrales los define como soluciones de esquina que se pueden utilizar como refuerzos en las construcciones, con la finalidad de fortalecer la unión entre materiales constructivos, bien del mismo material o bien de distinta naturaleza. El objetivo es aumentar la capacidad de resistencia de los muros en los que se insertan, como refuerzo a muros de mampostería, disponiéndose a la denominada “cremallera” (Corrales 2014: 275; Pizzo 2010: 409-411).

Así pues, tras este breve análisis de las técnicas y sistemas constructivos empleados en el nivel inferior de la Domus del Peristilo podemos concluir que la presencia de muros $10 \mathrm{~cm}$ más anchos que aquellos situados en el piso superior, reforzados con grandes sillares esquineros, junto con una ubicación idónea para ampliar el espacio edificable de la planta superior hacia el S, parecen confirmar que ambos planos se encontraban relacionados, al menos desde el punto de vista constructivo. 


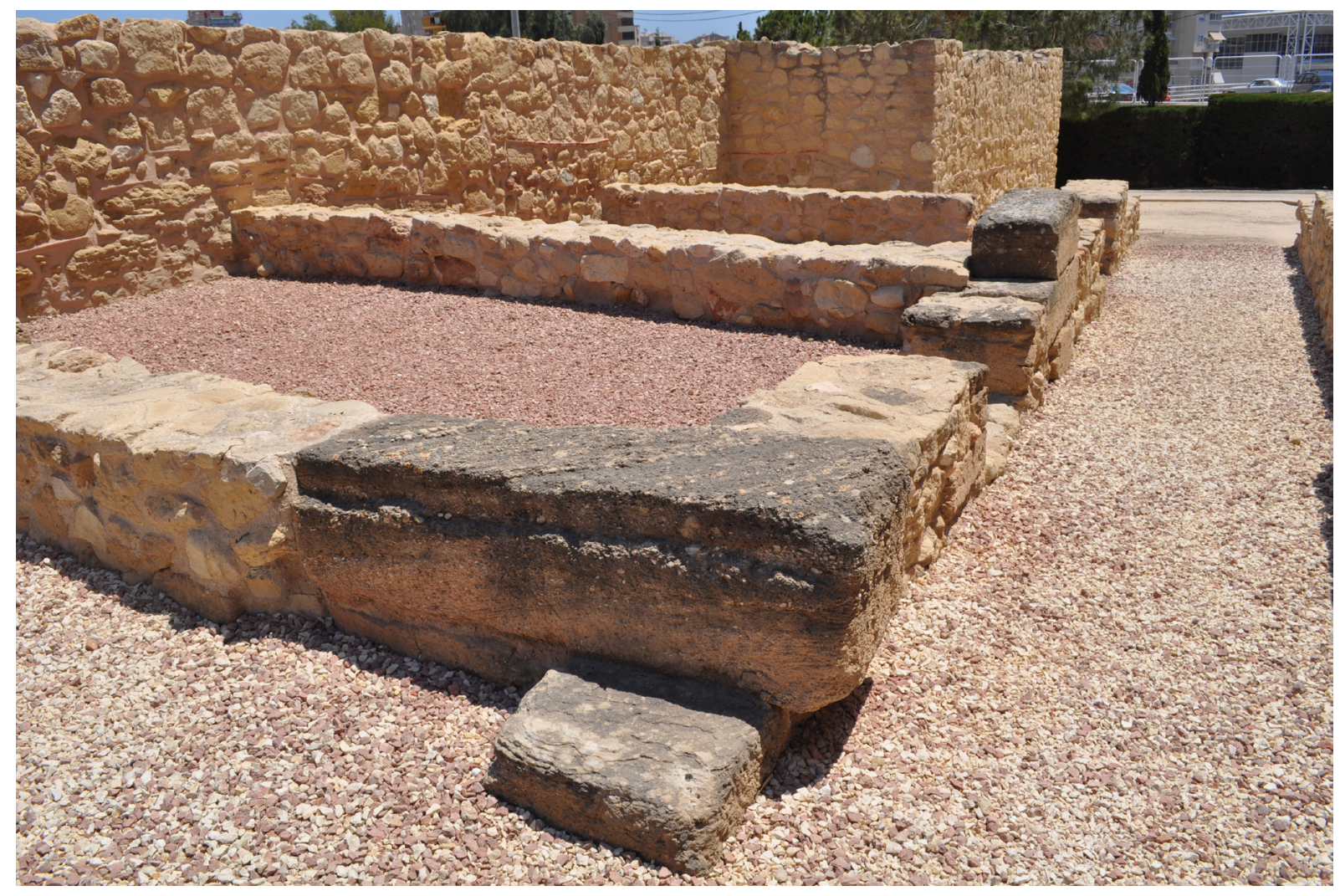

Figura 8. Sillares esquineros del nivel inferior de la Domus del Peristilo.

\section{PROBLEMAS CONSTRUCTIVOS COMUNES, SOLUCIONES SIMILARES}

El hecho de que la Domus del Peristilo, con el acceso directo al patio porticado, no coincida con el tradicional concepto de casa itálica canónica viene a reforzar la teoría sobre la gran diversidad de ámbitos domésticos en el mundo romano, ya defendida por Tamm (1973), y actualmente reconocida en el mundo de la investigación sobre domus romanas. Paralelos de distribución similar encontramos en la casa de Iulius Polybius, que consta de un peristilo con tres pórticos, o la Casa de $\mathrm{Pi}$ narius Cerialis (III 4, 6) (Pompeya), con un plano irregular que se organiza en torno a los dos lados de un jardín cuadrado porticado, con una entrada mediante escaleras, que se abre directamente en la parte $\mathrm{N}$ del mismo (Richardson 1997: 343-344). Además, esta vivienda inutilizó la muralla del lado SO de la ciudad. Otra domus que presenta un peristilo de similares características es la Domus I, 13, 1 (Pompeya), definida en su momento como «un impianto domestico anomalo» (Gallo 1988: 156), con un espacio central ajardinado ocupado por un pórtico columnado en L. El área abierta ocupa una forma rectangular rodeada por un pórtico en sus lados $\mathrm{E}$ y $\mathrm{S}$, mientras un muro de 0,65 $\mathrm{m}$ de altura máxima, como el murete que encontramos en la Domus del Peristilo, servía de unión entre las columnas y separaba el área descubierta del deambulatorio (Gallo 1988: 156-159).

Por consiguiente, y pese a no tratarse de una domus "canónica", la Domus del Peristilo de Lucentum encuentra diversos paralelos fortuitos en Pompeya, lo que sin duda nos indica la gran variabilidad de modelos en la propia urbe campana, que no responden necesariamente al modelo ideal de domus vitruviana.

Pero hay un fenómeno que queremos analizar en mayor profundidad, referido no a la morfología de la domus, sino a su adaptación al urbanismo y al espacio edificable disponible. En la propia Lucentum observamos cómo la primera fase de la Domus de la Puerta Oriental ( $\mathrm{Lu}$ centum) anula la parte NE de la muralla (Olcina y Pérez 2003: 100). En otras ciudades hispanas como Mérida, durante los periodos de paz las casas se adosan a las murallas romanas, cuyo paso de ronda, ya en el s. I d.C., se vio invadido por viviendas reformadas, que acabaron por adosarse al muro defensivo (Alba 2001: 403). 
En Pompeya, las zonas occidental y meridional de la ciudad se convierten en los lugares residenciales preferidos por la élite. La selección parece responder a la costumbre de construir lujosas habitaciones en lugares panorámicos, donde poder conciliar los negocios y la vida en la ciudad, con la tranquilidad y la amoenitas de una villa extraurbana. Para satisfacer esta demanda se necesitaba un gran gasto de espacio, difícil de encontrar en el centro de la urbe, razón por la que se recurría a áreas suburbanas y a las murallas destituidas de su función defensiva, cambiando su orientación a favor de los intereses privados (Jacobelli 2001: 33-34).

En la Insula Occidentalis, sobre la pendiente O de la ciudad campana, a lo largo de un área aproximadamente de $15.000 \mathrm{~m}^{2}$, se encuentran 15 lujosas habitaciones con la característica común de estar articuladas en niveles con terrazas y jardines abiertos al mar (Aoyagi y Pappalardo 2006: 17). Su morfología resulta de la fusión entre el modelo romano itálico de la casa de atrio con aquel de la villa suburbana. En esta ínsula pompeyana, las terrazas abiertas sobre el golfo, que originalmente se construyeron apoyándose en los muros como la casa de M. Fabio Rufo, posteriormente se ampliaron sobre la muralla aprovechando el desnivel a ambos lados de la misma (Aoyagi y Pappalardo 2006: 38-40).

Las casas de la Regio VIII, 2 en el lado SO, coincidentes con la orientación que tiene la Domus del Peristilo de Lucentum, tienen dimensiones considerables, probablemente habitadas por una clase bienestante, interesada en el aspecto panorámico y climático, con una óptima exposición de los ambientes, inundados de sol durante el invierno y frescos en verano. La tipología de estas casas no sigue el eje atrio-tablino-peristilo, sino que se dispone sobre diversos niveles y además, no aparece orientada hacia la calle sino hacia el mar, al cual se abre a través de las ventanas (Jacobelli 2001: 34-35).

Por tanto, la élite social de la primera mitad del s. I d.C. se situó sobre las pendientes de la ciudad una vez que los muros habían perdido su función defensiva con la fundación de la colonia, ya que desde esta parte se podía gozar de un panorama del golfo de Sorrento. Las puertas de ingreso de estas casas se mantienen ligadas al sistema de las calles, mientras el espacio doméstico se abre sobre el paisaje, lo que proporcionaba el elemento esencial de la nueva cultura (Zanker 1993:158-160).

El mismo fenómeno se produce en Herculano, mirando hacia el $\mathrm{S}$ y el $\mathrm{O}$, con la incomparable vista de la bahía de Nápoles. La evidencia muestra cómo se abandonaron las funciones defensivas de las paredes, permitiendo a los propietarios extender sus casas, destruyendo parapetos y ganando las vistas. Es evidente que en estos casos, teniendo en cuenta que se trataría de una propiedad pública, este proceso tenía que ser aprobado en el consejo local; un buen ejemplo de ello es la Casa de los Ciervos, con sus salas de recepción que miran al mar. Las casas de la Insula Orientalis I, ubicadas también sobre la muralla, como la Casa del Relieve de Telefo y la Casa de la Gema, sitúan el peristilo de modo que mira al mar o al río y a la bahía, su morfología permite la sucesión de habitaciones a distintas alturas y niveles, todas ellas con diversas vistas (Wallace-Hadrill 2011: 233-246).

Todas estas características se cumplen de igual manera en la Domus del Peristilo que, construida sobre la muralla púnica obsoleta, abriría sus salas de representación al mar (del que actualmente dista solo $240 \mathrm{~m}$ ), con una privilegiada vista panorámica (fig. 9). Mientras, su entrada principal se mantiene conectada a una de las principales arterias de la ciudad.

De manera que observamos cómo esta solución constructiva se da en ciudades marítimas, que abren sus vistas al mar, con el factor común de que inutilizan la estructura defensiva previa, que en esos momentos se considera obsoleta, como base constructiva de las estancias de representación.

A este fenómeno se une la tendencia a situar las residencias más lujosas en sectores periféricos de la urbe, para evitar los centros densamente poblados, en ocasiones debido a que se trataba de fundaciones romanas ubicadas sobre un sustrato indígena previo. Estos escenarios eran poco favorables a la creación de domus que exigían un minimum de superficie, por lo que las amplias mansiones se implantan entonces en los barrios limítrofes. En Timgad (N de África), las grandes residencias no pudieron desplegar su magnificencia más que en los barrios periféricos y desbordaron rápidamente la muralla original o se situaron en el mismo emplazamiento de la misma, demolida a consecuencia de las obras inmobiliarias (Thébert 1991: 329-330). Con esto se produce una diferenciación social de los distintos barrios, las ricas viviendas de notables no se levantan en la primitiva ciudad encorsetada, sino que se dirigen a los espacios que habían quedado libres por la demolición de las murallas. Lo mismo sucede en Banasa (Marruecos), donde el centro masificado por el entramado ortogonal de la época de Augusto desplaza a la periferia las casas de los notables. 


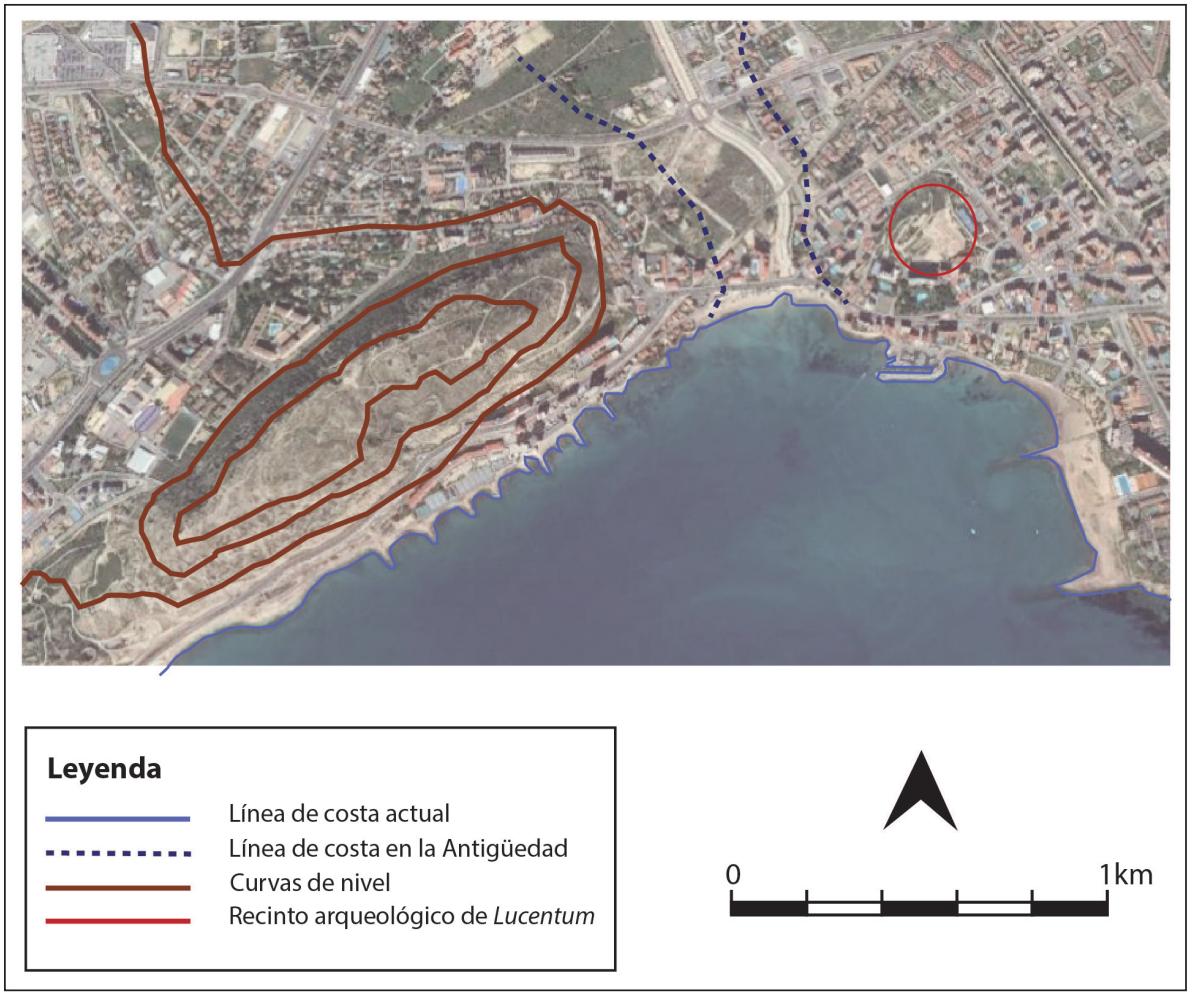

Figura 9. Situación de Lucentum y su relación con el entorno (elaboración propia a partir de Martínez y Moreno 2015: 279).

\section{CONCLUSIONES}

En conclusión, nos encontramos frente a un espacio doméstico altoimperial, de unos $400 \mathrm{~m}^{2}$ estimados, cuya morfología evidencia la gran cantidad de variables que intervienen en el diseño y construcción de una domus, siendo en este caso especialmente relevantes las cuestiones topográficas y de espacio edificable. Esta domus se construye superando la antigua muralla púnica, posteriormente republicana, que en época altoimperial se consideró obsoleta. Esta solución constructiva otorgó la posibilidad de crear dos niveles, que si bien no podemos afirmar con rotundidad que pertenecieron a la misma domus, a pesar de que tanto los materiales como las técnicas constructivas de ambos pisos sean los mismos, podemos estar seguros de que se encontraban interconectados por cuestiones logísticas. Para ello hemos llevado a cabo un estudio de las técnicas constructivas que vienen a confirmar, mediante el grosor de los muros del nivel inferior $(60 \mathrm{~cm}, 10 \mathrm{~cm}$ más que los del primer nivel) y la presencia de sillares esquineros, que estos espacios extramuros sostendrían un primer nivel, conectado con el viario urbano, que en función de la lógica constructiva albergaría las estancias de representación ausentes y esperables en torno al patio porticado, que constituiría el distribuidor central de la vivienda.

El estudio de paralelos nos permite observar cómo en varios puntos del Imperio, las exigencias de espacio edificable en ciudades romanas ubicadas sobre antiguos centros indígenas dieron lugar a soluciones constructivas similares, que llevaron a destruir o utilizar las obsoletas estructuras defensivas previas. De este modo se ganaba terreno urbanizable y además, en el caso de ciudades costeras, se potenciaban las panorámicas a las que se abrirían las estancias de representación. Por otra parte, y frente a la diferencia de cota generada por este tipo de construcciones, se desarrolla un sistema constructivo, el de las substrucciones, que ofrece numerosas posibilidades de uso, entre las que se encuentran las de estancias de servicio, que proponemos cumplieron las estancias del nivel inferior de la Domus del Peristilo.

Nuestra intención en este artículo ha sido la de plantear diversas hipótesis, que consideramos factibles a través del estudio comparativo con diversos paralelos y que permiten realizar una relectura, que nos ayuda a ampliar nuestro conocimiento sobre una de las domus más emblemáticas del municipium de Lucentum. 


\section{Agradecimientos}

A José Luis Jiménez por su asesoramiento. Al equipo arqueológico de Lucentum dirigido por Manuel Olcina, por prestarme su ayuda y facilitarme el acceso al yacimiento. Este trabajo se ha realizado gracias a la financiación del Programa FPU del Ministerio de Educación, Cultura y Deporte (convocatoria 18/11/2013).

\section{Bibliografía}

Alba, M. (2001): “Características del viario de Emerita entre los siglos I-VIII”. Mérida ciudad y patrimonio 5: 397-423.

Älfoldy, G. (2003): “Administración, urbanización, instituciones, vida pública y orden social", en L. Abad y J. M. Abascal (coords.), Las ciudades y los campos de Alicante en época romana, Canelobre 48: 35-57. Alicante, Instituto Alicantino de Cultura Juan Gil-Albert.

Aoyagi, M. y Pappalardo, U. (2006): Pompei (Regiones VI-VII). Insula Occidentalis. Nápoles, Valtrend Editore.

Basso, P. (2003): "I vani di deposito-stoccaggio", en P. Basso y F. Ghedini (eds.), Subterraneae Domus. Ambienti residenziali e di servizio nell'edilizia privata romana: 519-566. Verona, Cierre Edizioni.

Bonetto, J. (2003): 'L'uso del sottosuolo nell'edilizia domestica della Tunisia romana", en S. Bullo y F. Ghedini (eds.), Amplissimae atque ornatissimae domus. L'edilizia residenziale nelle città della Tunisia romana: 281-297. Roma, Edizioni Quasar.

Bonini, P. (2006): La casa nella Grecia Romana. Forme e funzioni dello spazio privato fra I e VI secolo. Milán, Edizioni Quasar.

Bonini, P. (2016): "Le cucine nell'Italia romana: domus e villae", en G. Cuscito (coord.), L'alimentazione nell'antichità. Atti della XLVI settimana di studi aquileiesi: 455-474. Aquileia (2015), Trieste, Editreg.

Bonini, P. y Rinaldi, F. (2003): "Gli ambienti di servicio”, en S. Bullo y F. Ghedini (eds.), Amplissimae atque ornatissimae domus. L'edilizia residenziale nelle città della Tunisia romana: 189-220. Roma, Edizioni Quasar.

Corrales, A.; Bermejo, J. y Campos J. M. (2016): “La arquitectura doméstica urbana de las ciudades occidentales del Conventus Hispalensis: un ejercicio de crítica historiográfica". Lucentum 35: 201-215.

Cortés, A. (2014): “The peristyle house and porticated court house: similarities and differences between the two", en XVIII CIAC: Centro y periferia en el mundo clásico: 1013-1017. Mérida (2013), Mérida, Museo Nacional de Arte Romano.

Fernández, A. (2000-2001): “Algunos restos pictóricos de la ciudad de Lucentum (Tossal de Manises-Alicante)". Lucentum 19-20: 215-236.

Foss, P. (1994): Kitchens and dining rooms at Pompeii: the spatial and social relationship of cooking to eating in the roman household. Tesis doctoral, University of Michigan. https://www.researchgate. net/publication/34798817_Kitchens_and_dining_ rooms_at_Pompeii_the_spatial_and_social_relationship_of_cooking_to_eating_in_the_Roman household, 28/08/2017, [05/09/2017].

Gallo, A. (1988): "Saggi di scavo nella Domus I, 13, 1". Rivista di studi pompeiani 2: 154-184.

García, C. (2014): "Estancias subterráneas en las domus hispanorromanas del valle oriental del Duero: Los casos de Clunia, Uxama y Termes", en XVIII CIAC: Centro y periferia en el mundo clásico: 1093-1096. Mérida (2013), Mérida, Museo Nacional de Arte Romano.

Jacobelli, L. (2001): "Pompei fuori le mura: Lo spazio pubblico e privato", en F. Senatore (ed.), Pompei tra Sorrento e Sarno. Atti del terzo e quarto ciclo di conferenze di geologia, storia e archeologia: 29-61. Pompei (1999-2000), Roma, Bardi.

Kastenmeier, P. (2007): I luoghi del lavoro domestico nella casa pompeiana. Roma, L'Erma di Bretschneider.

Lafuente, J. (1932): Alicante en la Antigüedad. Alicante, Gráficas Gutenberg.

Martínez, J. y Moreno, J. (2015): "Nunc autem a Gothis subversa: the province of Alicante and the Spanish Mediterranean towns between the Byzantine and Visigothic periods". Early Medieval Europe 3, vol. 23: 263-289.

Meyer, K. E. (1999): "Axial peristyle houses in the western empire". Journal of Roman Archaeology 12: 101-121.

Moret, P.; Muñoz, A.; García, I.; Callegarin, L. y Prados, F. (2008): "El oppidum de la Silla del Papa (Tarifa, Cádiz) y los orígenes de Baelo Claudia”. Aljaranda $68: 2-8$.

Olcina, M. (2006): "Lucentum: origin and evolution of a Roman municipium in the Sinus Ilicitanus", en L. Abad Casal; S. Keay y S. Ramallo (eds.), Early roman towns in Hispania Tarraconensis. JRA Suppl.62: 105-117. Portsmouth, Journal of Roman Archaeology.

Olcina, M. (2009): Lucentum (Tossal de Manises, Alicante). Arqueología e historia. Alicante, Museo Arqueológico de Alicante. 
Olcina, M.; Guilabert, A. y Tendero, E. (2014): “Lucentum: El municipi de Lucentum", en M. H. Olcina (ed.), Actas de las Jornadas sobre Ciudades Romanas Valencianas. Actualidad de la investigación historicoarqueológica: 200-216. Alicante (2013), Alicante, Museo Arqueológico de Alicante.

Olcina, M.; Guilabert, A. y Tendero, E. (2015): “Lucentum: el paisaje urbano augusteo, en Tarraco Biennal. Actes $2^{o_{n}}$ Congrés Internacional d'Arqueologia $i$ Mon Antic, August $i$ les provincies occidentals 2000 Aniversari de la Mort D'August: 255-262. Tarragona (2014), Tarragona, Fundació Privada Mútua Catalana.

Olcina, M. y Pérez, R. (2003): "Lucentum: La ciudad y su entorno", en L. Abad y J. M. Abascal (coord.), Las ciudades y los campos de Alicante en época romana, Canelobre 48: 91-119. Alicante, Instituto Alicantino de Cultura Juan Gil-Albert.

Pizzo, A. (2010): Las técnicas constructivas de la arquitectura pública de Augusta Emerita. Madrid, Instituto de Arqueología de Mérida.

Richardson, L. (1997): Pompeii. An Architectural History. London, The Johns Hopkins University Press.

Roldán, L.; Macias, J. M.; Pizzo, A. y Rodríguez, O. (2017): "Acerca del proyecto Modelos constructivos y urbanísticos de la arquitectura de Hispania: Definición, evolución y Difusión. Del periodo romano a la antigüedad tardía (MARQUIS)", en L. Roldán; J. M. Macias; A. Pizzo; O. Rodríguez (eds.), Modelos constructivos y urbanísticos de la arquitectura de Hispania. Documenta 29: 7-14. Tarragona, Institut Català d'Arqueologia Clàssica (ICAC).

Sáenz, J. C.; Fabre, J.; Lasuén, M.; Luesma, R.; Sevilla, A. y Villalba, I. (2005): "La casa del Ninfeo de Bílbilis (Calatayud, Zaragoza). Intervención arqueológica de la Escuela Taller de Restauración de Aragón”. Saldvie 5: 377-396.
Salza, E. (1978-1980): "Cucine e quartieri servili in epoca romana". Atti della Pontificia Accademia romana di archeologia 51-52: 237-294.

Sarabia, J. (2013): "La casa romana como espacio de conciliación entre el ámbito doméstico y la representación socio-económica del dominus. Algunos casos de estudio del Conventus Carthaginiensis", en S. Gutiérrez e I. Grau (coords.), De la estructura doméstica al espacio social: lecturas arqueológicas del uso social del espacio: 179-181. Alicante, $\mathrm{Pu}-$ blicaciones Universidad de Alicante.

Tamm,B. (1973): "Some notes on roman houses". Opuscula Romana 9: 53-60.

Tarradell, M. y Martín, G. (1970): “Els antigons-Lucentum. Una ciudad romana en el casco urbano de Alicante". Papeles de laboratorio de Valencia 8: 7-28.

Thébert, Y. (1991): "Vida privada y arquitectura doméstica en el África romana", en P. Ariès y G. Dubi, (eds.), Historia de la vida privada. Imperio romano y antigüedad tardía: 303-397. Madrid, Taurus Ediciones.

Uribe, P. (2008): La edilicia doméstica urbana romana en el cuadrante Nordeste de la Península Ibérica (ss. I a. C. - III d. C.). Tesis doctoral, Universidad de Zaragoza. https://zaguan.unizar.es/ record/1890?ln=es\#, 30/06/2008, [26/06/2015].

Uribe, P. (2015): La arquitectura doméstica urbana romana en el valle medio del Ebro (siglos II a.C.- III p.C.). Burdeos, Aquitania.

Wallace-Hadrill, A. (2011): Herculaneum. Past and future. Londres, Frances Lincoln Limited Publishers.

Zaccaria, M. (2003): "Substructiones", en P. Basso y F.Ghedini (eds.), Subterraneae Domus. Ambienti residenziali e di servizi nell'edilizia privata romana: 65-100. Verona, Cierre Edizioni.

Zanker, P. (1993): Pompei. Società, immagini urbane e forme del abitare. Turín, Giulio Einaudi Editore. 